\title{
The Effects of 2'-O-Methoxyethyl Containing Antisense Oligonucleotides on Platelets in Human Clinical Trials
}

\author{
Stanley T. Crooke, Brenda F. Baker, Joseph L. Witztum,2 T. Jesse Kwoh, ${ }^{1}$ Nguyen C. Pham, \\ Nelson Salgado,' Bradley W. McEvoy,' Wei Cheng,' Steven G. Hughes, \\ Sanjay Bhanot, and Richard S. Geary ${ }^{1}$
}

A thorough analysis of clinical trial data in the Ionis integrated safety database (ISDB) was performed to determine if there is a class effect on platelet numbers and function in subjects treated with $2^{\prime}$-O $O$-methoxyethyl (2'MOE)-modified antisense oligonucleotides (ASOs). The Ionis ISDB includes over 2,600 human subjects treated with 16 different $2^{\prime} \mathrm{MOE}$ ASOs in placebo-controlled and open-label clinical trials over a range of doses up to $624 \mathrm{mg} /$ week and treatment durations as long as 4.6 years. This analysis showed that there is no class generic effect on platelet numbers and no incidence of confirmed platelet levels below $50 \mathrm{~K} / \mu \mathrm{L}$ in subjects treated with 2'MOE ASOs. Only 7 of 2,638 (0.3\%) subjects treated with a 2'MOE ASO experienced a confirmed postbaseline (BSLN) platelet count between 100 and $50 \mathrm{~K} / \mu \mathrm{L}$. Three of sixteen $2^{\prime}$ MOE ASOs had $>10 \%$ incidence of platelet decreases $>30 \%$ from BSLN, suggesting that certain sequences may associate with clinically insignificant platelet declines. Further to these results, we found no evidence that 2 'MOE ASOs alter platelet function, as measured by the lack of clinically relevant bleeding in the presence or absence of other drugs that alter platelet function and/or number and by the results from trials conducted with the factor XI (FXI) ASO.

Keywords: antisense, safety, platelets, thrombocytopenia, factor XI

\section{Introduction}

$\mathbf{R}$ ECENTLY, WE REPORTED that severe thrombocytopenic events occurred in two placebo-controlled phase 3 studies with two different $2^{\prime}$ - $O$-methoxyethyl (2'MOE)modified antisense oligonucleotides (ASOs), IONIS-TTR Rx and volanesorsen. Although, moderate thrombocytopenia has been reported for a $2^{\prime} \mathrm{MOE}$ ASO in patients with multiple sclerosis [1], we had not experienced any severe thrombocytopenic event in any clinical trial before these recent events. Given these observations, we have performed a detailed examination of the effects of this chemical class of ASOs on platelets. In this article, we report the analysis of our broad clinical experience with $2^{\prime} \mathrm{MOE}$ ASOs to determine if there is a chemical class effect on platelet numbers and function using our integrated 2'MOE safety database (ISDB), [2].

The Ionis ISDB includes clinical data for sixteen $2^{\prime} \mathrm{MOE}$ ASOs from this second-generation chemical class (Table 1). All 2'MOE ASO drugs within this class have similar chemical and physical characteristics - including the number of nucleobases, sugar-phosphorothioate backbone, molecular weight, charge, and solubility. These shared characteristics result in similar pharmacokinetic and pharmacodynamic profiles and provide the opportunity to identify and characterize potential class effects. The availability of placebocontrolled data from 42 phase 1-3 trials supported critical examination of this class of 16 distinct $2^{\prime} \mathrm{MOE}$ ASO sequences at various doses and in a variety of target populations (Table 2). Furthermore, data collected in the open-label extension trials allowed an assessment for any effects that may stem from long-term exposure.

The ISDB currently contains laboratory test results for over 2,600 human subjects dosed systemically with a $2^{\prime} \mathrm{MOE}$ ASO [ $86 \%$ subcutaneously (SC); $8 \%$ intravenous infusion (IV); and $6 \% \mathrm{SC}$ and IV]. In this population, $\sim 1,000$ subjects have been treated for 3 months or longer with drug exposure up to 4.6 years, resulting in a total exposure of $\sim 800$ subjectyears. As an entirely new chemical and pharmacological class of therapeutics, 2'MOE ASOs have undergone thorough preclinical and clinical evaluations. The construction of the first safety database that integrates all observations from nonhuman primates (NHPs) and all clinical studies is an invaluable tool that is available at Ionis Pharmaceuticals. Our plan is to publish multiple articles describing the results of

\footnotetext{
${ }^{1}$ Ionis Pharmaceuticals, Inc., Carlsbad, California.

${ }^{2}$ Department of Medicine, University of California San Diego, School of Medicine, La Jolla, California.
}

(c) Stanley T. Crooke et al. 2017; Published by Mary Ann Liebert, Inc. This article is available under the Creative Commons License CC-BYNC (http://creativecommons.org/licenses/by-nc/4.0). This license permits non-commercial use, distribution and reproduction in any medium, provided the original work is properly cited. Permission only needs to be obtained for commercial use and can be done via RightsLink. 
Table 1. 2 - $O$-Methoxyethyl Antisense Oligonucleotides with Clinical Data IN THE InTEgRated SAFEty Database

\begin{tabular}{|c|c|c|c|c|c|c|}
\hline ISIS no. & Target & Sequence $\left(5^{\prime} 3^{\prime}\right)^{\mathrm{a}}$ & Design & Trials $^{\mathrm{b}}$ & Total, $\mathrm{n}$ & $A S O, \mathrm{n}$ \\
\hline 107248 & CD49D & CTGAGTCTGTTTTCCATTCT & $3-9-8$ & 1 & 54 & 36 \\
\hline 104838 & TNFA & GCTGATTAGAGAGAGGTCCC & $5-10-5$ & 5 & 281 & 212 \\
\hline 113715 & PTP1B & $\overline{\text { GCTCCTTCCACTGATCCTGC }}$ & $5-10-5$ & 9 & 301 & 236 \\
\hline 301012 & APOB & GCCTCAGTCTGCTTCGCACC & $5-10-5$ & 21 & $1,414^{\mathrm{c}}$ & 1,091 \\
\hline 304801 & APOCIII & AGCTTCTTGTCCAGCTTTAT & $5-10-5$ & 3 & 136 & 99 \\
\hline 329993 & CRP & AGCATAGTTAACGAGCTCCC & $5-10-5$ & 4 & 173 & 129 \\
\hline 404173 & PTP1B & AATGGTTTATTCCATGGCCA & $5-10-5$ & 2 & 140 & 98 \\
\hline 416858 & FXI & ACGGCATTGGTGCACAGTTT & $5-10-5$ & 3 & 408 & 312 \\
\hline 420915 & TTR & TCTTGGTTACATGAA ATCCC & $5-10-5$ & 1 & 65 & 51 \\
\hline 426115 & GCCR & $\overline{\text { GCAGCCATGGTGATCAGGAG }}$ & $5-10-5$ & 2 & 95 & 65 \\
\hline 449884 & GCGR & GGTTCCCGAGGTGCCCA & $3-10-4$ & 2 & 126 & 88 \\
\hline 463588 & FGFR4 & $\overline{\mathrm{GCA}} \mathrm{CACTCAGCAG \overline {GACC } C C C}$ & $5-10-5$ & 1 & 48 & 36 \\
\hline 494372 & LPA & TGCTCCGTTGGTGCTTGTTC & $5-10-5$ & 2 & 111 & 72 \\
\hline 505358 & HBV & $\overline{\text { GCAGAGGTGAAGCGAAGTGC }}$ & $5-10-5$ & 1 & 28 & 21 \\
\hline 546254 & PKK & 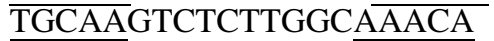 & $5-10-5$ & 1 & 49 & 37 \\
\hline 563580 & ANGPTL3 & $\overline{\text { GGACATTGCCAGTAATCGCA }}$ & $5-10-5$ & 1 & 47 & 35 \\
\hline Total & 15 & 16 & & 59 & 3,476 & 2,618 \\
\hline
\end{tabular}

Underline indicates 2'MOE-modified sugar residues.

${ }^{2}$ 'MOE ASOs were phosphorothioate modified and all cytosine (C) residues were methylated at the five position.

${ }^{\mathrm{b}}$ See Supplementary Table S1 for additional details on trial designs and development phase.

${ }^{\mathrm{c}}$ Cohorts investigating oral bioavailability were excluded.

ASOs, antisense oligonucleotides; 2'MOE, 2'-O-methoxyethyl.

analyses from the ISDB in peer-reviewed journals, so the data will be broadly available. In fact, the first of this series of articles is published [2]. In that publication, we have compiled the safety and tolerability data of $2^{\prime} \mathrm{MOE}$ ASOs in NHPs and in normal human volunteers. The published phase 1 data set [2] contained data from 12 unique 2'MOE ASOs with a total of 733 healthy volunteer systemic exposures (549 active, 184 placebo) for durations up to 6 weeks ( 8 doses). No remarkable reductions in platelet counts were observed over the course of multidose treatment in this phase 1 data set. The only incident of confirmed platelet counts below $75 \mathrm{~K} / \mu \mathrm{L}$ occurred in a placebo-treated subject.

\section{Materials and Methods}

Data collected from 52 completed, randomized, placebocontrolled, and open-label trials were analyzed. (Supplementary

Table 2. Disease Indications Tested IN $2^{\prime}$ - $O$-METHOXYETHYL ANTISENSE

Oligonucleotide Phase 2 and Phase 3 Trials

\begin{tabular}{|c|c|c|c|}
\hline Indication & Targets & $\begin{array}{c}\text { ASO } \\
\text { doses } \\
(\mathrm{mg} / \text { week })\end{array}$ & $\begin{array}{l}\text { Treatment } \\
\text { (weeks) }\end{array}$ \\
\hline $\begin{array}{l}\text { Cardiovascular } \\
\text { disease }\end{array}$ & $\begin{array}{l}\text { APOB } \\
\text { APOCIII } \\
\text { LPA }\end{array}$ & $30-400$ & $5-52$ \\
\hline Diabetes/obesity & $\begin{array}{l}\text { PTP1B } \\
\text { GCCR } \\
\text { GCGR } \\
\text { FGFR4 } \\
\text { APOCIII }\end{array}$ & $100-600$ & $4-26$ \\
\hline Thrombosis & FXI & $100-300$ & 6 \\
\hline $\begin{array}{l}\text { Inflammation/ } \\
\text { autoimmune }\end{array}$ & $\begin{array}{l}\text { CRP } \\
\text { TNFA }\end{array}$ & $100-400$ & $4-13$ \\
\hline Pancreatitis & APOCIII & $100-300$ & 13 \\
\hline
\end{tabular}

Tables S1 and S2; Supplementary Data are available online at www.liebertpub.com/nat). Phase 1 trials based on a crossover design, for example, drug-drug interaction investigations, were analyzed separately (Supplementary Tables S3 and S4). All data were from completed trials or unblinded and completed interim lock data. Data collected from oncology trials were excluded from the analyses since the large majority of cancer patients were treated with a 2 'MOE ASO in combination with cytotoxic agents and no trials were placebo controlled [3-9]. An independent assessment of longer-term $2^{\prime} \mathrm{MOE}$ ASO treatment on platelet counts and bleeding events was also performed, but was limited to data available from the phase 3 and open-label extension trials on mipomersen (ISIS 301012). To enable comparisons with prior publications, we have utilized the ISIS numbers for these $2^{\prime} \mathrm{MOE}$ ASOs as all were designed and tested before we changed our name to Ionis Pharmaceuticals.

Data were analyzed by the incidence of platelet events and by descriptive summary statistics of platelet results. Analyses on the incidence of platelet events were based on confirmed test results. A confirmed event was defined as a consecutive (next) abnormal laboratory value after the initial observation. If there was no consecutive test to confirm, then the initial observation was presumed confirmed. In phase 1 trials, platelet counts were evaluated weekly. In phase 2 and phase 3 trials, platelet counts were assessed on average every 2 and 4 weeks, respectively. As a result, the observations reported on a per-subject basis are much more frequent than if based on the number of platelet count assessments. Effects on platelet function were addressed by summation of bleeding events using standardized MedDRA queries.

\section{Statistical analysis}

Evaluated subjects were those who received at least one dose of study drug and had at least one postbaseline (BSLN) platelet count and were included in the analyses. Any 
additional limitations, specific to an analysis, are provided by footnote. BSLN was defined as the last value before the first dose.

A meta-analysis using subject-level data was performed to investigate the relationship between dose level and change in platelet levels in randomized placebo-controlled trials (RCTs) (Supplementary Tables S5-S7 and Supplementary Figs. S1, S2). Cohorts from RCTs were included in the metaanalysis, provided the protocol-specified study drug was (1) administered SC; (2) administered more than once, that is, no single-dose cohorts; and (3) in a single-dose category assignment (mg/week) for all subjects in the cohort as randomized. The meta-analysis was limited to platelet values collected during the treatment period, defined as the period from first dose to last dose plus 10 days.

The following endpoints were evaluated in the metaanalyses: percent change from BSLN using the last nonmissing platelet value in the treatment period and confirmed decrease $>30 \%$ from BSLN. Two types of comparisons were performed for each endpoint. The first comparison investigated the relationship between the separate $2^{\prime} \mathrm{MOE}$ ASO dose levels $(>0-75,>75-175$, >175-275, >275-375, >375$475 \mathrm{mg} /$ week) and placebo. The second type of comparison investigated adjacent 2'MOE ASO dose levels (eg, >0$75 \mathrm{mg} /$ week vs. placebo, $>75-175 \mathrm{mg} /$ week vs. $>0-75 \mathrm{mg} /$ week).

To preserve the integrity of randomization, stratified statistical methods were used to analyze the data. For the four categorical endpoints, the difference in response rate between a 2'MOE ASO dose level and placebo or the adjacent 2'MOE ASO dose level was estimated using the stratified MantelHaenszel method for a common risk difference, with trial as the stratification factor. For the continuous endpoint, the difference in the average percent change between a $2^{\prime} \mathrm{MOE}$ ASO dose level and placebo or the adjacent $2^{\prime} \mathrm{MOE}$ ASO dose level was estimated using an analysis of covariance (ANCOVA) model, with dose level, trial, and BSLN platelet level as independent variables in the model. Tabulated summaries of each meta-analysis are provided as Supplementary Tables S8 and S9.

\section{Results \\ Low incidence of clinically relevant decreases in platelets}

Evaluation of the integrated data from phase 1, 2, and 3 clinical trials and open-label extension trials showed only six subjects with a confirmed post-BSLN platelet count $<100-75$ $\mathrm{K} / \mu \mathrm{L}(6 / 2,249$ or $0.3 \%)$ and only one $(0.04 \%)$ subject with a confirmed count $<75-50 \mathrm{~K} / \mu \mathrm{L}$. There were no ASO-treated subjects with a confirmed platelet count below $50 \mathrm{~K} / \mu \mathrm{L}$ ( "A" in Table 3). All seven ASO-treated subjects who experienced platelet counts $<100 \mathrm{~K} / \mu \mathrm{L}$ were from the higher $2^{\prime} \mathrm{MOE}$ ASO dose categories ( $>175 \mathrm{mg} /$ week). Two of these subjects were from an open-label extension trial with total $2^{\prime} \mathrm{MOE}$ ASO exposures of 1.0 and 4.4 years; three subjects were from shorter-term phase 2 trials and completed treatment with total 2'MOE ASO exposures from 6 to 26 weeks; and two subjects, one dosed at $210 \mathrm{mg} /$ week in a phase 3 trial and the other dosed at $400 \mathrm{mg} /$ week in a phase 2 trial, discontinued dosing after 37 and 9 weeks, respectively.

Milder platelet reductions resulting in on-treatment platelet levels between the lower limit of normal (LLN) and 100 $\mathrm{K} / \mu \mathrm{L}$ occurred more frequently in both placebo (1.7\%) and 2'MOE ASO-treated (4.8\%) subjects ("A" in Table 3). The incidence of platelet reductions was influenced by dose level, with an increase in incidence from $0.6 \%$ in the lowest ( $>0-75 \mathrm{mg} /$ week) to $7.5 \%$ in the highest $(>475 \mathrm{mg} /$ week) dose group. However, as the number of subjects $(n=40)$ in

Table 3. Incidence of Confirmed Platelet Reductions Across All Trials, Phase 1 to Phase 3

\begin{tabular}{|c|c|c|c|c|c|c|c|c|}
\hline \multirow{2}{*}{$\begin{array}{l}\text { Post-BSLN platelet count } \\
\text { Confirmed, }{ }^{\mathrm{b}} \mathrm{n}(\%)\end{array}$} & \multirow[b]{2}{*}{ Placebo } & \multirow[b]{2}{*}{ ASO total } & \multicolumn{6}{|c|}{ 2'MOE ASO dose, mg/week } \\
\hline & & & $>0-75$ & $>75-175$ & $>175-275$ & $>275-375$ & $>375-475$ & $>475$ \\
\hline (A) $n^{\mathrm{c}}$ & 749 & 2,249 & 158 & 344 & 1,231 & 257 & 219 & 40 \\
\hline $\mathrm{LLN}-100 \mathrm{~K} / \mu \mathrm{L}$ & $13(1.7)$ & $109(4.8)$ & $1(0.6)$ & $6(1.7)$ & $68(5.5)$ & $17(6.6)$ & $14(6.4)$ & $3(7.5)$ \\
\hline$<100-75 \mathrm{~K} / \mu \mathrm{L}$ & $0(0)$ & $6(0.3)$ & $0(0)$ & $0(0)$ & $4(0.3)$ & $1(0.4)$ & $1(0.5)$ & $0(0)$ \\
\hline$<75-50 \mathrm{~K} / \mu \mathrm{L}$ & $1(0.1)$ & $1(0.04)$ & $0(0)$ & $0(0)$ & $0(0)$ & $0(0)$ & $1(0.5)$ & $0(0)$ \\
\hline$<50-25 \mathrm{~K} / \mu \mathrm{L}$ & $0(0)$ & $0(0)$ & $0(0)$ & $0(0)$ & $0(0)$ & $0(0)$ & $0(0)$ & $0(0)$ \\
\hline$<25 \mathrm{~K} / \mu \mathrm{L}$ & $0(0)$ & $0(0)$ & $0(0)$ & $0(0)$ & $0(0)$ & $0(0)$ & $0(0)$ & $0(0)$ \\
\hline (B) $n$ & 777 & 2,363 & 161 & 361 & 1,300 & 267 & 233 & 41 \\
\hline$<0.7 \times$ BSLN & $13(1.7)$ & $205(8.7)$ & $2(1.2)$ & $10(2.8)$ & $121(9.3)$ & 37 (13.9) & $31(13.3)$ & $4(9.8)$ \\
\hline$<0.5 \times$ BSLN & $2(0.3)$ & $20(0.8)$ & $0(0)$ & $0(0)$ & $10(0.8)$ & $1(0.4)$ & $9(3.9)$ & $0(0)$ \\
\hline$n$ & 777 & 2,368 & 161 & 362 & 1,303 & 267 & 234 & 41 \\
\hline$<75 \mathrm{~K} / \mu \mathrm{L}$ & $1(0.1)$ & $4(0.2)$ & $0(0)$ & $0(0)$ & $1(0.1)$ & $1(0.4)$ & $1(0.4)$ & $1(2.4)$ \\
\hline$<50 \mathrm{~K} / \mu \mathrm{L}$ & $0(0)$ & $0(0)$ & $0(0)$ & $0(0)$ & $0(0)$ & $0(0)$ & $0(0)$ & $0(0)$ \\
\hline
\end{tabular}

Table presenting lowest platelet level achieved versus 2'MOE ASO dose administered. In panel (A), all subjects had BSLN platelet levels within the normal range (LLN-ULN), while Panel (B) includes an additional 142 subjects whose BSLN levels were outside the range of normal.

${ }^{a}$ Data collected on and after protocol-specified procedures, for example, total knee arthroplasty and endotoxin bolus; from nonplacebo comparator groups, and trials based on a crossover design, for example, drug-drug interaction trials were excluded.

${ }^{\mathrm{b}}$ Confirmed was defined as a consecutive (next) abnormal laboratory value after the initial observation. If there was no consecutive test to confirm, then the initial observation was presumed confirmed.

${ }^{c}$ Number of subjects from 52 trials with normal baseline platelet counts and with postbaseline values. Lowest confirmed category was reported for each subject.

BSLN, baseline; LLN, lower limit of normal; ULN, upper limit of normal. 
Table 4. Incidence of Confirmed Postbaseline Platelet Reductions with Mipomersen Treatment

\begin{tabular}{|c|c|c|c|c|c|c|}
\hline \multirow{2}{*}{$\begin{array}{l}\text { Post-BSLN platelet counts } \\
\text { Confirmed, }{ }^{\mathrm{a}} \mathrm{n}(\%)\end{array}$} & \multicolumn{2}{|c|}{ Total phase 3 RCT } & \multicolumn{2}{|c|}{ 6-Month phase 3 RCT } & \multicolumn{2}{|c|}{ 1-Year phase 3 RCT } \\
\hline & Placebo total & MIPO total & Placebo & MIPO & Placebo & MIPO \\
\hline$n^{\mathrm{b}}$ & 221 & 433 & 121 & 249 & 100 & 184 \\
\hline LLN-100 K/ $\mu \mathrm{L}$ & $6(2.7)$ & $27(6.2)$ & $5(4.1)$ & $16(6.4)$ & $1(1.0)$ & $11(6.0)$ \\
\hline$<100-75 \mathrm{~K} / \mu \mathrm{L}$ & $0(0)$ & $1(0.2)$ & $0(0)$ & $0(0)$ & $0(0)$ & $1(0.5)$ \\
\hline$<75-50 \mathrm{~K} / \mu \mathrm{L}$ & $0(0)$ & $0(0)$ & $0(0)$ & $0(0)$ & $0(0)$ & $0(0)$ \\
\hline$<50-25 \mathrm{~K} / \mu \mathrm{L}$ & $0(0)$ & $0(0)$ & $0(0)$ & $0(0)$ & $0(0)$ & $0(0)$ \\
\hline$<25 \mathrm{~K} / \mu \mathrm{L}$ & $0(0)$ & $0(0)$ & $0(0)$ & $0(0)$ & $0(0)$ & $0(0)$ \\
\hline
\end{tabular}

${ }^{\text {a }}$ Confirmed was defined as a consecutive (next) abnormal laboratory value after the initial observation. If there was no consecutive test to confirm, then the initial observation was presumed confirmed.

${ }^{\mathrm{b}}$ Number of subjects with normal BSLN platelet counts and with post-BSLN values. Lowest confirmed category was reported for each subject.

MIPO, mipomersen; RCT, randomized placebo-controlled trial.

the $>475 \mathrm{mg} /$ week dose group was limited, the incidence in the high-dose group is yet to be defined.

The percentage of subjects who experienced decreases in platelet counts $>30 \%$ from BSLN was $1.7 \%$ in placebo and averaged $8.7 \%$ in ASO-treated subjects ("B"' in Table 3), and again, increased with increasing $2^{\prime} \mathrm{MOE}$ ASO dose. Among the $472^{\prime} \mathrm{MOE}$ ASO-treated subjects with BSLN counts lower than the LLN, only 3 reached a value $<75-50 \mathrm{~K} / \mu \mathrm{L}$. Thus, while platelet decreases were influenced by dose level, the incidence of clinically relevant platelet decreases was very low in $2^{\prime} \mathrm{MOE}$ ASO-treated subjects.

\section{No increase in clinically relevant platelet decreases with longer-term mipomersen treatment}

Assessment of the effect of longer-term 2'MOE ASO treatment on platelet levels was limited to data available from phase 3 and open-label extension trials for one drug in this class, mipomersen (ISIS 301012). This dataset is derived from four 6-month RCTs, one 1-year RCT, and two open-label extension studies. Approximately $80 \%$ of the subjects in these trials were diagnosed with familial hypercholesterolemia.

The incidence of mild platelet reductions in mipomersentreated subjects was similar in the 6-month and 1-year placebo-controlled trials (Table 4). Of note, only one subject $(0.5 \%)$ had confirmed platelet counts less than $100 \mathrm{~K} / \mu \mathrm{L}$ in the 1-year trial. Based on the analysis of the entire phase 1 to phase 3 dataset (Table 3 ), there was not a single incident of a confirmed platelet drop below $50 \mathrm{~K} / \mu \mathrm{L}$ in subjects treated with mipomersen for as long as 4.6 years. Thus, there was no increased incidence of clinically relevant platelet decreases in longer-term, placebo-controlled phase 3 trials. Assessment of all RCTs found that the confirmed platelet counts below $100 \mathrm{~K} / \mu \mathrm{L}$ did not occur until after at least a month of dosing.

To determine if more frequent dosing might result in a higher incidence of platelet declines, we compared platelet counts in subjects treated with either mipomersen $200 \mathrm{mg}$ weekly or $70 \mathrm{mg}$ three times weekly $(210 \mathrm{mg} /$ week) in the 1 year trial. The incidence of the post-BSLN platelet reductions in the LLN-100 K/ $\mu \mathrm{L}$ bracket was about the same between the two dose regimens.

\section{Three 2 MOE ASOs responsible for increase in mild platelet declines}

The incidence of $30 \%$ reduction in platelet levels from BSLN appears to be influenced by the $2^{\prime} \mathrm{MOE}$ ASO sequence. Only three of sixteen $2^{\prime}$ MOE ASOs (19\%) displayed a $>10 \%$ overall incidence of platelet decreases in ASO-treated subjects, suggesting that the effect of treatment on platelet levels is affected by sequence (Table 5). None of the sixteen $2^{\prime} \mathrm{MOE}$ ASOs, however, had a higher incidence than placebo in the lower dose range ( $<175 \mathrm{mg} /$ week), another indication that the effect on platelets is influenced by dose level. Closer inspection of phase 2 data for each of the three 2'MOE ASOs showed that these decreases in platelet levels were time and dose dependent. As an example, the effects of several dose levels of ISIS 104838 (TNF $\alpha)$ are shown in Fig. 1.

Table 5. Proportion of $2^{\prime}$ - $O$-Methoxyethyl Antisense Oligonucleotides with $>10 \%$ Incidence of Confirmed Platelet Reductions $>30 \%$ From Baseline $(<0.7 \times$ BSLN $)$

\begin{tabular}{|c|c|c|c|c|c|c|c|c|}
\hline \multirow{2}{*}{$\frac{\text { Post-BSLN platelet count }^{\mathrm{a}}}{\text { Confirmed }^{\mathrm{b}}}$} & \multirow[b]{2}{*}{ Placebo } & \multirow[b]{2}{*}{ ASO total } & \multicolumn{6}{|c|}{ 2'MOE ASO dose (mg/week) } \\
\hline & & & $>0-75$ & $>75-175$ & $>175-275$ & $>275-375$ & $>375-475$ & $>475$ \\
\hline $\begin{array}{l}\text { Subjects, } n^{\mathrm{c}} \\
\quad \text { Platelet }<0.7 \times \text { BSLN }, n(\%)\end{array}$ & $\begin{array}{c}777 \\
13(1.7)\end{array}$ & $\begin{array}{c}2,363 \\
205(8.7)\end{array}$ & $\begin{array}{c}161 \\
2(1.2)\end{array}$ & $\begin{array}{c}361 \\
10(2.8)\end{array}$ & $\begin{array}{c}1,300 \\
121(9.3)\end{array}$ & $\begin{array}{c}267 \\
37(13.9)\end{array}$ & $\begin{array}{c}233 \\
31(13.3)\end{array}$ & $\begin{aligned} & 41 \\
4(9.8) & -1\end{aligned}$ \\
\hline $\begin{array}{l}\text { ASO, } n \\
\quad>10 \% \text { incidence, } n(\%)\end{array}$ & $\begin{array}{c}16 \\
0(0)\end{array}$ & $\begin{array}{l}16 \\
3(19)\end{array}$ & $\begin{array}{r}16 \\
0(0)\end{array}$ & $\begin{array}{c}16 \\
0(0)\end{array}$ & $\begin{array}{l}15 \\
3(20)\end{array}$ & $\begin{array}{ll} & 12 \\
3 & (25)\end{array}$ & $\begin{array}{ll} & 15 \\
6(40)\end{array}$ & $\begin{array}{c}4 \\
2(50)\end{array}$ \\
\hline
\end{tabular}

${ }^{a}$ Data collected on and after protocol-specified procedures, for example, total knee arthroplasty and endotoxin bolus; and studies based on a crossover design, for example, drug-drug interaction studies are excluded.

${ }^{\mathrm{b}}$ Confirmed was defined as a consecutive (next) abnormal laboratory value after the initial observation. If there was no consecutive test to confirm, then the initial observation was presumed confirmed.

${ }^{\mathrm{c}}$ Number of subjects from 52 trials with a platelet value at BSLN and at least one post-BSLN value. 


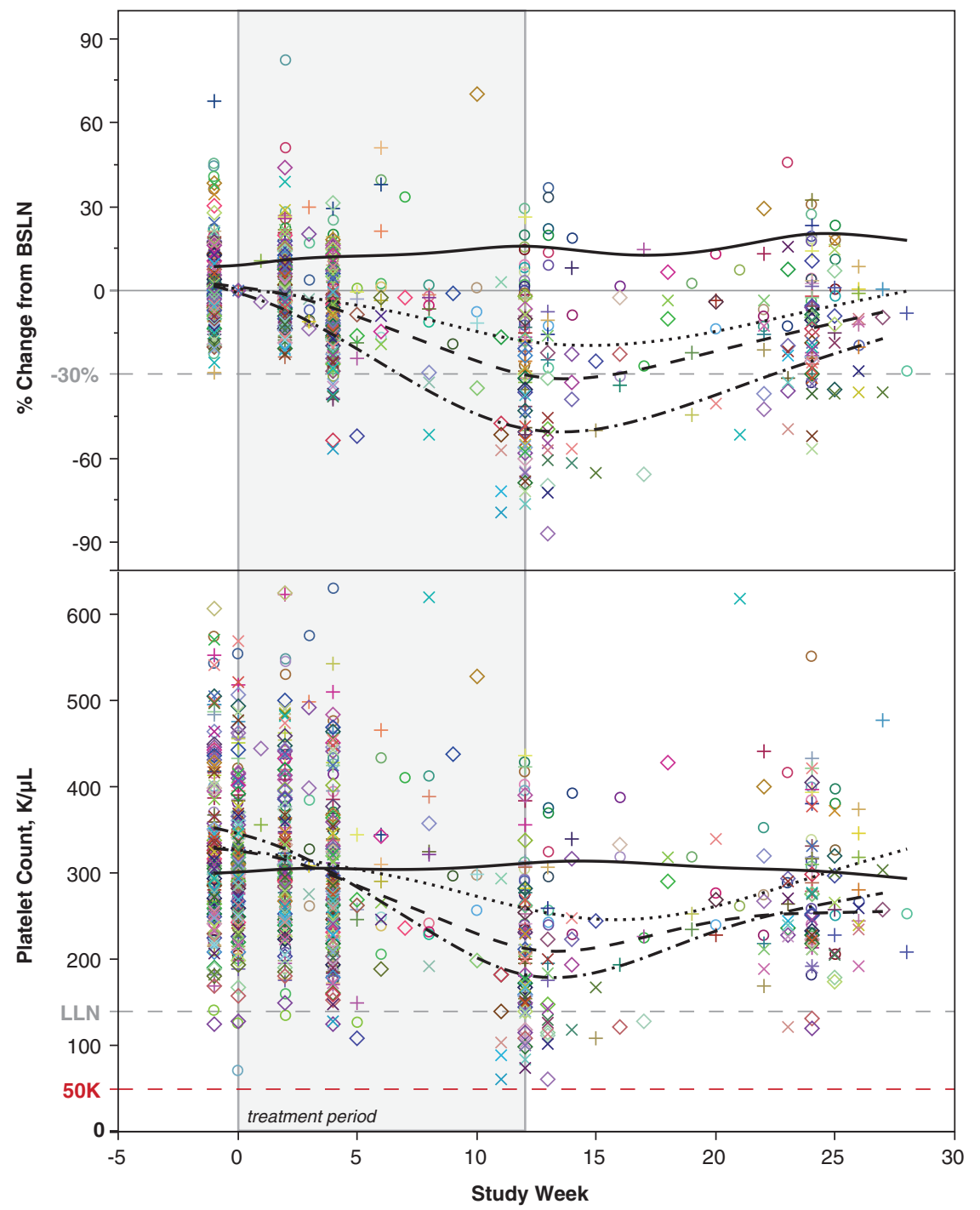

FIG. 1. Platelet levels over time in subjects with rheumatoid arthritis treated with ISIS 104838, which targets $\mathrm{TNF} \alpha$, in a 12-week, randomized, placebo-controlled phase 2 trial. Top panel shows the percent change from baseline and the bottom panel shows the absolute platelet count over time. Data lines represent dose group: - placebo, ‥ $100 \mathrm{mg} /$ week, - - $200 \mathrm{mg} /$ week, and $-\cdot-400 \mathrm{mg} /$ week. Symbols represent individual subject data. Vertical gray lines indicate the first and last dose of the 12-week treatment period.

\section{MOE ASO treatment does not affect platelet function}

To determine if $2^{\prime}$ MOE ASO treatment has an effect on platelet function, an assessment of platelet levels and bleeding events was performed in the context of (1) concomitant medications utilized to mitigate and reduce the risk of thrombosis and (2) clinical settings where there is a high risk for bleeding. The incidence of bleeding events was utilized as a measure of platelet function.

The placebo-controlled, 6-month phase 3 dataset was utilized to assess the incidence of confirmed platelet reductions and bleeding events in subjects who reported antithrombotic and/or antiplatelet concomitant medications compared with those who did not report these specific concomitant medications. Reported antithrombotic and antiplatelet concomitant medications included platelet aggregation inhibitors, aspirin, heparin products, and warfarin. See supplementary Data for a tabulated summary of these medications (Supplementary Table S10).

This assessment found a higher incidence of confirmed platelet reductions within the range of $L L N$ to $100 \mathrm{~K} / \mu \mathrm{L}$ for those subjects reporting concomitant dosing with antithrombotic agents with normal BSLN levels ("A" in Table 6), but a comparable incidence of confirmed platelet reduction of $30 \%$ or more from BSLN $(<0.7 \times$ BSLN $)$ in the presence or absence of antithrombotic agents ("B" in Table 6). Importantly, there was once again no platelet count below $50 \mathrm{~K} /$ $\mu \mathrm{L}$ and only one $(0.4 \%)$ less than $75 \mathrm{~K} / \mu \mathrm{L}$.

The incidence of bleeding events related to study drug was $1.6 \%$ in placebo-treated subjects and $1.1 \%$ in mipomersentreated subjects during the 6-month treatment period (Table 7 and Supplementary Table S11). All events were mild in severity and occurred predominantly in subjects who reported usage of antithrombotic or antiplatelet concomitant medications.

In addition to assessment of bleeding events, we also performed an analysis on two coagulation parameters, activated partial thromboplastin time (APTT) and prothrombin time (PT), to provide a more thorough evaluation of the effects of 2'MOE ASO treatment on bleeding. In this analysis, we assessed data collected from subjects in RCTs for the incidence of prolongation in APTT or PT while on treatment. Results from this analysis showed no dose-dependent effect of ASO treatment on the incidence of abnormalities in these coagulation tests compared with placebo (Supplementary Table S12). Since this analysis determined the effects of 
Table 6. Incidence of Confirmed Platelet Reductions in Subjects Reporting Usage of Antithrombotic Concomitant Medications in 6-Month, Phase 3, Randomized Placebo-Controlled Trials

\begin{tabular}{|c|c|c|c|c|c|c|}
\hline \multirow{3}{*}{$\frac{\text { Post-BSLN platelets confirmed, }{ }^{\mathrm{a}} \mathrm{n}(\%)}{\text { Treatment period }}$} & \multicolumn{3}{|c|}{ No usage of antithrombotic agents } & \multicolumn{3}{|c|}{ Usage of antithrombotic agents } \\
\hline & \multirow{2}{*}{$\begin{array}{l}\text { Placebo } \\
(\mathrm{n}=43)\end{array}$} & \multirow{2}{*}{$\begin{array}{c}M I P O \\
(\mathrm{n}=69)\end{array}$} & \multirow{2}{*}{$\begin{array}{c}\text { Total } \\
(\mathrm{n}=112)\end{array}$} & \multirow{2}{*}{$\begin{array}{c}\text { Placebo } \\
(\mathrm{n}=86)\end{array}$} & \multirow{2}{*}{$\begin{array}{c}M I P O \\
(\mathrm{n}=192)\end{array}$} & \multirow{2}{*}{$\begin{array}{c}\text { Total } \\
(\mathrm{n}=278)\end{array}$} \\
\hline & & & & & & \\
\hline (A) $n^{\mathrm{b}}$ & 39 & 64 & 103 & 82 & 182 & 264 \\
\hline $\mathrm{LLN}-100 \mathrm{~K} / \mu \mathrm{L}$ & $1(2.6)$ & $2(3.1)$ & $3(2.9)$ & $1(1.2)$ & $10(5.5)$ & $11(4.2)$ \\
\hline$<100-75 \mathrm{~K} / \mu \mathrm{L}$ & $0(0)$ & $0(0)$ & $0(0)$ & $0(0)$ & $0(0)$ & $0(0)$ \\
\hline$<75-50 \mathrm{~K} / \mu \mathrm{L}$ & $0(0)$ & $0(0)$ & $0(0)$ & $0(0)$ & $0(0)$ & $0(0)$ \\
\hline$<50-25 \mathrm{~K} / \mu \mathrm{L}$ & $0(0)$ & $0(0)$ & $0(0)$ & $0(0)$ & $0(0)$ & $0(0)$ \\
\hline$<25 \mathrm{~K} / \mu \mathrm{L}$ & $0(0)$ & $0(0)$ & $0(0)$ & $0(0)$ & $0(0)$ & $0(0)$ \\
\hline (B) $n$ & 42 & 65 & 107 & 86 & 188 & 274 \\
\hline$<0.7 \times$ BSLN & $0(0)$ & $5(7.7)$ & $5(4.7)$ & $0(0)$ & $14(7.4)$ & $14(5.1)$ \\
\hline$<0.5 \times \mathrm{BSLN}$ & $0(0)$ & $0(0)$ & $0(0)$ & $0(0)$ & $1(0.5)$ & $1(0.4)$ \\
\hline$N$ & 42 & 66 & 108 & 86 & 188 & 274 \\
\hline$<\mathrm{LLN}$ & $2(4.8)$ & $3(4.5)$ & $5(4.6)$ & $3(3.5)$ & $13(6.9)$ & $16(5.8)$ \\
\hline$<75 \mathrm{~K} / \mu \mathrm{L}$ & $0(0)$ & $0(0)$ & $0(0)$ & $0(0)$ & $1(0.5)$ & $1(0.4)$ \\
\hline$<50 \mathrm{~K} / \mu \mathrm{L}$ & $0(0)$ & $0(0)$ & $0(0)$ & $0(0)$ & $0(0)$ & $0(0)$ \\
\hline
\end{tabular}

Treatment period is defined as post first dose to last dose +10 days.

${ }^{a}$ Confirmed event was defined as a consecutive abnormal laboratory value on next measurement after the initial observation. If there was no consecutive test to confirm, then the initial observation was presumed confirmed.

${ }^{b}$ Number of subjects with normal BSLN platelet counts and with post-BSLN values. Lowest confirmed category was reported for each subject.

treatment on these coagulation parameters during the drug plasma elimination phase (vs. distribution phase), it represents the cumulative effects of multiple doses and is consistent with the well-characterized, transient concentration-dependent effect observed at peak plasma concentrations [10-16].

\section{Discussion}

In contrast to the recent observations in the volanesorsen familial chylomicronemia syndrome (FCS) trial and the IONIS-TTR $_{\mathrm{Rx}}$ trial, in completed placebo-controlled and open-label trials, 2'MOE ASOs did not produce clinically relevant platelet decreases. Among 2,368 subjects treated with $2^{\prime} \mathrm{MOE}$ ASOs $(\sim 800$-person years of experience in trials included in the ISDB), there were no subjects who had a confirmed platelet count below $50 \mathrm{~K} / \mu \mathrm{L}$ and only $7(0.3 \%)$ who experienced a platelet count between 100 and $50 \mathrm{~K} / \mu \mathrm{L}$. Further to these results, there was no evidence in the ISDB that $2^{\prime} \mathrm{MOE}$ ASOs alter platelet function, as measured by the lack of clinically relevant bleeding in the presence or absence of other drugs that alter platelet function and/or number.

TABle 7. InCidence of BleEding Events in 6-Month, Phase 3 Mipomersen Trials

\begin{tabular}{lcc}
\hline Treatment period & Placebo & MIPO \\
\hline$n$ & 129 & 261 \\
Any bleeding event, ${ }^{\text {a }} n(\%)$ & $2(1.6)$ & $3(1.1)$ \\
Antithrombotic agent, yes, $n(\%)$ & $2(1.6)$ & $2(0.8)$ \\
\hline
\end{tabular}

Table shows any bleeding event reported as possibly related, related, or of unknown relationship to study drug during the treatment period.

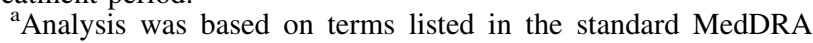
query. Events reported under the system organ class, general disorders, and administration site conditions are reported in the appendix (Supplementary Table S11).
Of particular value, in understanding the effect of $2^{\prime} \mathrm{MOE}$ ASO treatment on platelet function, was the phase 2, openlabel, randomized parallel-group trial in subjects undergoing total knee arthroplasty and fully anticoagulated with ISIS 416858 (IONIS-FXI Rx ) before and during surgery [17]. In this trial, reduction in factor XI (FXI) activity by IONIS-FXI $I_{R x}$ at $300 \mathrm{mg}$ SC weekly reduced the rate of venous thromboembolism by sevenfold compared with the standard of care enoxaparin treatment, following total knee replacement surgery. Factor XI activity levels were reduced to a mean absolute level of $0.2 \mathrm{U} / \mathrm{mL}$ in the $300 \mathrm{mg} /$ week IONIS-FXI $\mathrm{Rx}_{\mathrm{x}}$-treated group compared with $0.93 \mathrm{U} / \mathrm{mL}$ in the enoxaparin comparator group. Although subjects were fully anticoagulated at the time of surgery with IONIS-FXI $\mathrm{Rx}_{\text {, clinically relevant }}$ bleeding was lower in IONIS-FXI $\mathrm{Rx}_{\mathrm{R}}$-treated subjects compared with enoxaparin (3\% vs. $8 \%$ ), although not statistically significant. Comparable results were observed in animal model studies following similar high-risk bleeding procedures [18-20]. These results indicate that there were no effects of 2 'MOE ASO treatment on platelet function even under conditions of surgical stress and reduced procoagulant activity.

A decrease in platelet count $>30 \%$ below BSLN levels occurred in up to $14 \%$ of subjects, which was influenced by dose and appeared to display some influence of sequence as it was observed primarily with three of the sixteen $2^{\prime} \mathrm{MOE}$ ASOs evaluated. These declines were not associated with any clinical consequences, nor appeared to change significantly with prolonged treatment or in the presence of anticoagulant use.

One 2'MOE ASO, ATL1102 targeting VLA4, has been reported to result in a greater incidence of mild platelet declines in a phase $2 \mathrm{a}$ study that involved subjects with relapsing-remitting multiple sclerosis [1]. Because we do not have access to the primary data, data from this study are not included in our database. Based on the publicly available data, $\sim 11 \%$ of subjects treated with ATL1102 at a dose of $400 \mathrm{mg} /$ week had a decrease in platelet counts below the 
LLN, including one occurrence of platelet counts $<75 \mathrm{~K} / \mu \mathrm{L}$. We conclude that these data, once again, demonstrate some sequence variability and that doses of $400 \mathrm{mg} / \mathrm{week}$ are more prone to result in reductions in platelets than lower doses.

Results from the current analyses of the ISDB have the following limitations. The trials used in one comparison (eg, $>0-75 \mathrm{mg}$ /week vs. placebo) were unlikely to be the same in another comparison (eg, $>75-175 \mathrm{mg} /$ week vs. placebo). Therefore, comparison of the effects was indirect and must be interpreted with caution. Important differences in trial characteristics (eg, duration, disposition of subjects) may exist and may have confounded any comparison. Long-term experience ( $>1$ year) was derived from studies on mipomersen only.

For members of the $2^{\prime} \mathrm{MOE}$ class, we have previously demonstrated that there are no generic class effects that are observed consistently across many sequences at similar doses. There are no class effects on the liver, kidney, cardiac, central nervous system, muscle, or bone marrow function [15]. We have also demonstrated that agents of this class do not have significant cytochrome P450-mediated or major transporter-mediated drug-drug interactions [21]. Moreover, broad therapeutic effects at doses with acceptable safety and tolerability have been demonstrated [17,22-29]. The analysis of the ISDB provides information that can support thoughtful risk-benefit decisions, but obviously, conclusions about the generic characteristics of a chemical class cannot be expected to predict all observations for a specific sequence or a specific clinical setting.

More recent versions of 2'MOE ASOs are subject to more intense screening during the drug discovery process. As a consequence, all $2^{\prime} \mathrm{MOE}$ ASOs that entered development after mipomersen are two to four times more potent than mipomersen [2]. Thus, in future studies, one can contemplate using doses of $200 \mathrm{mg} /$ week or lower in long-term studies. We believe that this will further enhance the risk-benefit of this class of drugs.

Importantly, numerous lines of evidence show that chemical modifications that might seem minor to scientists not intimate with the technology can have substantial effects on all pharmacological properties (for a review, see Crooke [30] and Vickers and Crooke [31]). For example, 2'-O-methylmodified ASOs are significantly less potent, more immune stimulatory, and associated with more frequent and severe adverse events than 2'MOE ASOs [32-34]. Thus, extrapolation from 2'MOE ASOs to other chemical classes of ASOs is inappropriate.

We are developing other chemical classes of ASOs that are substantially more potent than $2^{\prime} \mathrm{MOE}$ ASOs, including $2^{\prime}$ constrained ethyl $\left(2^{\prime} \mathrm{cEt}\right)$-modified ASOs and multivalent $\mathrm{N}$ acetylgalactosamine (GalNAc)-conjugated 2'MOE and 2' cEt ASOs [22]. We observe about a 10-fold increase in potency relative to $2^{\prime} \mathrm{MOE}$ ASOs for cEt ASOs and, with respect to liver targets, about a 30-fold increase in potency for GalNAc $2^{\prime} \mathrm{MOE}$ ASOs compared with the $2^{\prime} \mathrm{MOE}$ class. We currently have four $2^{\prime}$ cEt-modified and eight GalNAc-conjugated $2^{\prime} \mathrm{MOE}$ ASOs in development. As is being done for the $2^{\prime} \mathrm{MOE}$ class, we plan to publish the integrated safety information on these chemical classes as they become available.

Making definitive predictions about the behavior of a specific $2^{\prime} \mathrm{MOE}$ ASO based on the behavior of the chemical class is inappropriate. Different sequences may be identified that have specific adverse events and there can always be target or disease-related toxicities that must be assessed individually. However, such a database does provide useful information that supports more prudent decisions about development that can lead to lower risk for patients in clinical trials.

\section{Conclusion}

Evidence from randomized, placebo-controlled, and openlabel extension trials on sixteen $2^{\prime} \mathrm{MOE}$ ASOs in normal human subjects and patients with a variety of disorders has demonstrated that as a class, $2^{\prime} \mathrm{MOE}$ ASOs have resulted in no incidence of severe thrombocytopenia. However, mild self-limited reductions in platelet counts that have typically resulted in platelet levels above the LLN have been observed. More detailed analyses showed that the mild reductions in platelet counts were observed in trials on three of the $2^{\prime} \mathrm{MOE}$ ASOs included in the ISDB, suggesting that some sequences may result in mild clinically insignificant platelet declines. Thus, the severe thrombocytopenia observed in the FCS and TTR amyloidosis phase 3 trials appears to be unique. Efforts to understand the causes of the severe thrombocytopenic events are progressing and will be the subject of future reports, but preliminary evidence suggests that the mechanisms accounting for these events differ and are related to each of the diseases studied.

\section{Acknowledgments}

The authors thank Scott Henry and Frank Bennett for critical review of the manuscript; Junyi Yan, Di Yu, Doreen Chen, Dan Schulz, and Bill Jung for analytical and statistical support; and Tracy Reigle for graphics support, all from Ionis Pharmaceuticals.

\section{Author Disclosure Statement}

Joseph Witztum is a consultant to Ionis Pharmaceuticals. All other authors are employees of Ionis Pharmaceuticals.

\section{References}

1. Limmroth V, F Barkhof, N Desem, MP Diamond, G Tachas and ATL1102 Study Group. (2014). CD49d antisense drug ATL1102 reduces disease activity in patients with relapsingremitting MS. Neurology 83:1780-1788.

2. Crooke ST, BF Baker, TJ Kwoh, W Cheng, DJ Schulz, S Xia, N Salgado, HH Bui, CE Hart, et al. (2016). Integrated safety assessment of 2'-O-methoxyethyl chimeric antisense oligonucleotides in non-human primates and healthy human volunteers. Mol Ther 24:1771-1782.

3. Laskin JJ, G Nicholas, C Lee, B Gitlitz, M Vincent, Y Cormier, J Stephenson, Y Ung, R Sanborn, et al. (2012). Phase I/II trial of custirsen (OGX-011), an inhibitor of clusterin, in combination with a gemcitabine and platinum regimen in patients with previously untreated advanced non-small cell lung cancer. J Thorac Oncol 7: 579-586.

4. Saad F, S Hotte, S North, B Eigl, K Chi, P Czaykowski, L Wood, M Pollak, S Berry, et al.; Canadian Uro-Oncology Group. (2011). Randomized phase II trial of Custirsen (OGX-011) in combination with docetaxel or mitoxantrone as second-line therapy in patients with metastatic 
castrate-resistant prostate cancer progressing after firstline docetaxel: CUOG trial P-06c. Clin Cancer Res 17: 5765-5773.

5. Chi KN, SJ Hotte, EY Yu, D Tu, BJ Eigl, I Tannock, F Saad, S North, J Powers, ME Gleave and EA Eisenhauer. (2010). Randomized phase II study of docetaxel and prednisone with or without OGX-011 in patients with metastatic castration-resistant prostate cancer. J Clin Oncol 28:4247-4254.

6. Chia S, S Dent, S Ellard, PM Ellis, T Vandenberg, K Gelmon, J Powers, W Walsh, L Seymour and EA Eisenhauer. (2009). Phase II trial of OGX-011 in combination with docetaxel in metastatic breast cancer. Clin Cancer Res 15:708-713.

7. Natale R, F Blackhall, D Kowalski, R Ramlau, G Bepler, F Grossi, C Lerchenmüller, M Pinder-Schenck, J Mezger, et al. (2014). Evaluation of antitumor activity using change in tumor size of the survivin antisense oligonucleotide LY2181308 in combination with docetaxel for second-line treatment of patients with non-small-cell lung cancer: a randomized open-label phase II study. J Thorac Oncol 9:1704-1708.

8. Wiechno P, BG Somer, B Mellado, PL Chłosta, JM Cervera Grau, D Castellano, C Reuter, M Stöckle, J Kamradt, et al. (2014). A randomised phase 2 study combining LY2181308 sodium (survivin antisense oligonucleotide) with first-line docetaxel/prednisone in patients with castration-resistant prostate cancer. Eur Urol 65:516-520.

9. Hong DS, R Kurzrock, Y Oh, J Wheler, A Naing, L Brail, S Callies, V Andre, SK Kadam, et al. (2011). A phase 1 dose escalation, pharmacokinetic, and pharmacodynamic evaluation of eIF-4E antisense oligonucleotide LY2275796 in patients with advanced cancer. Clin Cancer Res 17:65826591.

10. Glover JM, JM Leeds, TG Mant, D Amin, DL Kisner, JE Zuckerman, RS Geary, AA Levin, and WR Shanahan, Jr. (1997). Phase I safety and pharmacokinetic profile of an intercellular adhesion molecule-1 antisense oligodeoxynucleotide (ISIS 2302). J Pharmacol Exp Ther 282:11731180.

11. Henry SP, W Novotny, J Leeds, C Auletta and DJ Kornbrust. (1997). Inhibition of coagulation by a phosphorothioate oligonucleotide. Antisense Nucleic Acid Drug Dev 7:503-510.

12. Sheehan JP and HC Lan. (1998). Phosphorothioate oligonucleotides inhibit the intrinsic tenase complex. Blood 92:1617-1625.

13. Sheehan JP and TM Phan. (2001). Phosphorothioate oligonucleotides inhibit the intrinsic tenase complex by an allosteric mechanism. Biochemistry 40:4980-4989.

14. Kwoh TJ. (2007). An overview of the clinical safety experience of first- and second generation antisense oligonucleotides. In: Antisense Drug Technology Principles, Strategies, and Applications, 2nd edition. Crooke ST, ed. CRC Press, New York, pp. 365-399.

15. Henry SP, T Kim, K Kramer-Strickland, TA Zanardi, RA Fey and AA Levin. (2007). Toxicologic properties of 2'-Omethoxyethyl chimeric antisense inhibitors in animals and man. In: Antisense Drug Technology Principles, Strategies, and Applications, 2nd edition. Crooke ST, ed. CRC Press, New York, pp. 327-363.

16. Sewell KL, RS Geary, BF Baker, JM Glover, TG Mant, RZ Yu, JA Tami and FA Dorr. (2002). Phase I trial of ISIS 104838 , a 2'-methoxyethyl modified antisense oligonucle- otide targeting tumor necrosis factor-alpha. J Pharmacol Exp Ther 303:1334-1343.

17. Büller HR, C Bethune, S Bhanot, D Gailani, BP Monia, GE Raskob, A Segers, P Verhamme and JI Weitz. (2015). FXIASO TKA Investigators. Factor XI antisense oligonucleotide for prevention of venous thrombosis. N Engl J Med 372:232-240.

18. Crosby JR, U Marzec, AS Revenko, C Zhao, D Gao, A Matafonov, D Gailani, AR MacLeod, EI Tucker, et al. (2013). Antithrombotic effect of antisense factor XI oligonucleotide treatment in primates. Arterioscler Thromb Vasc Biol 33:1670-1678.

19. Younis HS, J Crosby, JI Huh, HS Lee, S Rime, B Monia and SP Henry. (2012). Antisense inhibition of coagulation factor XI prolongs APTT without increased bleeding risk in cynomolgus monkeys. Blood 119:2401-2408.

20. Zhang H, EC Löwenberg, JR Crosby, AR MacLeod, C Zhao, D Gao, C Black, AS Revenko, JC Meijers, et al. (2010). Inhibition of the intrinsic coagulation pathway factor XI by antisense oligonucleotides: a novel antithrombotic strategy with lowered bleeding risk. Blood 116: 4684-4692.

21. Yu RZ, RS Geary, JD Flaim, GC Riley, DL Tribble, AA vanVliet and MK Wedel. (2009). Lack of pharmacokinetic interaction of mipomersen sodium (ISIS 301012), a 2'-Omethoxyethyl modified antisense oligonucleotide targeting apolipoprotein B-100 messenger RNA, with simvastatin and ezetimibe. Clin Pharmacokinet 48:39-50.

22. Viney NJ, JC van Capelleveen, RS Geary, S Xia, JA Tami, RZ Yu, SM Marcovina, SG Hughes, MJ Graham, et al. (2016). Antisense oligonucleotides targeting apolipoprotein(a) in people with raised lipoprotein(a): two randomized, double-blind, placebo-controlled, dose-ranging trials. Lancet 388:2239-2253.

23. Finkel RS, CA Chiriboga, J Vajsar, JW Day, J Montes, DC De Vivo, M Yamashita, F Rigo, G Hung, et al. (2016). Nusinersen treatment of infantile-onset spinal muscular atrophy. Lancet 388:3017-3026.

24. Duell PB, RD Santos, B-A Kirwan, JL Witztum, S Tsimikas and JJP Kastelein. (2016). Long-term mipomersen treatment is associated with a reduction in cardiovascular events in patients with familial hypercholesterolemia. J Clin Lipidol 10:1011-1021.

25. Gaudet D, VJ Alexander, BF Baker, D Brisson, K Tremblay, W Singleton, RS Geary, SG Hughes, NJ Viney, et al. (2015). Antisense inhibition of apolipoprotein C-III in patients with hypertriglyceridemia. N Engl J Med 373:438-447.

26. Santos RD, PB Duell, C East, JR Guyton, PM Moriarty, W Chin and RS Mittleman. (2015). Long-term efficacy and safety of mipomersen in patients with familial hypercholesterolaemia: 2-year interim results of an open-label extension. Eur Heart J 36:566-575.

27. Tsimikas S, NJ Viney, SG Hughes, W Singleton, MJ Graham, BF Baker, JL Burkey, Q Yang, SM Marcovina, et al. (2015). Antisense therapy targeting apolipoprotein(a): a randomised, double-blind, placebo-controlled phase 1 study. Lancet 386:1472-1483.

28. Gaudet D, D Brisson, K Tremblay, VJ Alexander, W Singleton, SG Hughes, RS Geary, BF Baker, MJ Graham, RM Crooke and JL Witztum. (2014). Targeting APOC3 in the familial chylomicronemia syndrome. N Engl J Med 371: 2200-2206.

29. Raal FJ, RD Santos, DJ Blom, AD Marais, MJ Charng, WC Cromwell, RH Lachmann, D Gaudet, JL Tan, et al. (2010). 
Mipomersen, an apolipoprotein B synthesis inhibitor, for lowering of LDL cholesterol concentrations in patients with homozygous familial hypercholesterolaemia: a randomised, double-blind, placebo-controlled trial. Lancet 375:9981006.

30. Crooke ST, ed. (2007). Antisense Drug Technology Principles, Strategies, and Applications, 2nd edition. CRC Press, New York.

31. Vickers TA and ST Crooke. (2016). Development of a quantitative BRET affinity assay for nucleic acid-protein interactions. PLoS One 11:e0161930.

32. Goemans NM, M Tulinius, $M$ van den Hauwe, AK Kroksmark, G Buyse, RJ Wilson, JC van Deutekom, SJ de Kimpe, A Lourbakos and G Campion. (2016). Long-term efficacy, safety, and pharmacokinetics of drisapersen in Duchenne muscular dystrophy: results from an open-label extension study. PLoS One 11:e0161955.

33. FDA Briefing Document, NDA 206031. Drisapersen, Peripheral and Central Nervous System Drugs Advisory Committee Meeting (November 24, 2015), www.fda.gov/ downloads/advisorycommittees/committeesmeetingmaterials/ drugs/peripheralandcentralnervoussystemdrugsadvisory committee/ucm473737.pdf (accessed on September 22, 2016).

34. Bianchini D, A Omlin, C Pezaro, D Lorente, R Ferraldeschi, D Mukherji, M Crespo, I Figueiredo, S Miranda, et al. (2013). First-in-human phase I study of EZN-4176, a locked nucleic acid antisense oligonucleotide to exon 4 of the androgen receptor mRNA in patients with castrationresistant prostate cancer. Br J Cancer 109:2579-2586.

Address correspondence to: Stanley T. Crooke, $M D, P h D$

Ionis Pharmaceuticals, Inc. 2855 Gazelle Court Carlsbad, CA 92011

E-mail: scrooke@ionisph.com

Received for publication October 4, 2016; accepted after revision December 15, 2016. 